\title{
Exploring Organizational Readiness Factors for New Technology Implementation within Non-Profit Organizations
}

\author{
Haneen Wraikat'1, Al Bellamy², He Tang3 \\ ${ }^{1}$ College of Technology, Eastern Michigan University, Ypsilanti, USA \\ ${ }^{2}$ School of Technology and Professional Development Services Management, Eastern Michigan University, Ypsilanti, USA \\ ${ }^{3}$ School of Engineering Technology, Eastern Michigan University, Ypsilanti, USA \\ Email: abellamy@emich.edu
}

How to cite this paper: Wraikat, H., Bellamy, A. and Tang, H. (2017) Exploring Organizational Readiness Factors for New Technology Implementation within NonProfit Organizations. Open Journal of Social Sciences, 5, 1-13.

$\underline{\text { https://doi.org/10.4236/jss.2017.512001 }}$

Received: October 28, 2017

Accepted: December 3, 2017

Published: December 6, 2017

Copyright () 2017 by authors and Scientific Research Publishing Inc. This work is licensed under the Creative Commons Attribution International License (CC BY 4.0).

http://creativecommons.org/licenses/by/4.0/

\begin{abstract}
This study examined the impact of organizational structure, organizational climate, technology implementation strategy, and employee perceptions of their psychological contract on employee's acceptance of a management information system within non-profit organizations. A sample of one hundred employees from three different nonprofit organizations in Southeast Michigan was surveyed; analysis of the data revealed a positive correlation for the relationship between employee technology acceptance and organizational climate. A positive correlation was also found between employee technology acceptance and organizational structure factors (organizational centralization, organizational integration, and organizational formalization). A positive correlation was revealed between employee technology acceptance and implementation strategy, and a positive correlation exists between employee perceptions of their psychological contract and employee technology acceptance.
\end{abstract}

\section{Keywords}

Organizational Structure, Organizational Climate, Psychological Contract, Non-Profit Organizations

\section{Introduction}

The purpose of this study was to explore factors that constitute an assessment of organizational readiness of nonprofit organizations for implementing management information systems (MIS). Billions of dollars are spent each year on new technology implementation at a variety of different organizations in the United 
States. A study by Munir and Phillip (2002) [1] concluded that many new technology implementations are unsuccessful. More than $70 \%$ of standard management information systems (MIS) implementation projects fail [2]. Critical implementation processes have to be explored before implementation, including how to start these processes in order to enhance the viability of the MIS [3]. Furthermore, organizations face numerous problems after introducing a new technology; therefore, it is crucial to perform a careful pre-implementation study that examines organizational readiness factors such as organizational climate, structure, employee's perception of their psychological contract and technology implementation strategy [4].

Nonprofit organizations are moving toward the adoption of information technology (IT) into their operations [5] [6] [7] in an attempt to grow and expand their services by becoming more efficient [7].

In the United States, more than six percent of all organizations are in the nonprofit sector. This translates to at least 1.6 million nonprofit organizations and almost ten percent of the work force [8]. Many of the nonprofit organizations are funded primarily by the federal government for all different programming and background operations, including departments of communication, information technology, and human resources [9]. Information technology at some nonprofits is not considered essential, and funding related to information technology projects is scarce and very costly [10]. For this reason, a successful implementation process and plan is crucial. Most nonprofit organizations have very limited budgets and are unable to cover any expenses not related to serving clients [11].

Information technology is generally limited to large nonprofit organizations because small nonprofit organizations can't afford it, as it requires a computer systems infrastructure and system experts. According to most nonprofits, information technology is secondary to their mission; as Schneider (2003) stated, "Small nonprofits cannot afford adequate technology, instead, they choose limited computerized systems to fit budgets and agency knowledge, and they need training to use systems effectively, because information systems are secondary to mission, small NPOs do not give them the priority needed to effectively develop tools that can aid agency activities" (p. 384) [12]. Organizational readiness is an important factor in a nonprofit organizations new information technology system implementation process.

Introducing a new technology such as a new MIS may result in numerous changes within each department in an organization. This is especially true in a nonprofit organization, where major pressure occurs in communicating with the federal government on how to share vital information securely and more effectively [10].

Implementing a new technology system impacts every aspect of organizational activity including enrolling clients and recording their demographic information into the system [12]. Furthermore, the use of information technology is essential for attracting donors, for remaining competitive with other nonprofits in the 
same geographic area, and managing the organization's resources more effectively [13].

This study focused on examining factors related to organizational readiness consisting of organizational climate, organizational structure, technology implementation strategy, employee perceptions of their psychological contract, and employee technology acceptance within nonprofit organizations.

\section{Literature Review}

\section{Nonprofit Organizations and the Need for Assessment}

The main goal of a nonprofit organizations implementing new technology is to increase efficiency and productivity for supporting the organization's mission. Most research has focused on organizational attitudes about IT and how it is adopted in profit organizations [5] [6]. The limited budget of small, nonprofit organizations affects their ability to adapt information systems and, in turn, affects their ability to serve communities effectively, in both managerial and programmatic ways [12]. The (Schneider, 2003) study states:

[A] study of nonprofit organizations serving the African American and Latino communities in Kenosha found that the nonprofits that could not effectively use IT often lost out on funding opportunities because they had trouble meeting expectations for proposal quality and record-keeping systems that both private and governmental funders now expect. [12]

Only a few studies have focused on factors such as organizational climate, structure, technology implementation strategy, and employees' technology acceptance of a new MIS implementation within non-profit organizations. Even fewer studies have examined the impact of employee perceptions of their psychological contract on their willingness to accept new technology in a nonprofit organization [5] [6] [7].

Nonprofit organizations are under constant pressure to adhere to budget restrictions and funders, third-party expectations and guidelines. It's a very difficult challenge for a nonprofit to budget any amount for any reason not related to serving clients, per Haddad et al. (2016), who state, "Trade-off between complying with their social values and day-to-day operations: nonprofit organization face continuously trade-off decisions between timely and cost-effective operations performance and the need to serve the society in full, without resource restrictions" (p. 635) [11]. As a result, further studies are needed to examine information technology implementation and organizational readiness factors that enable nonprofit organizations to make budget wise decisions related to information technology.

Nonprofit organizations are in constant competition with other nonprofit organizations and even with for-profit organizations, there is a need for further research on the organizational readiness of nonprofit organizations.

As nonprofit organizations are faced with many growing challenges, which include lack of government funding, there is a demand for more services, but 
very few resources. Information technology is the key to reducing some of these challenges and becoming more efficient

\subsection{Organizational Readiness for Change to New Technology}

A study by Hameed et al. (2012) defines organizational readiness as "the degree to which an organization has the awareness, resources, commitment and governance to adopt an IT system" (p. 20) [14]. The same study found that organizational readiness is a major factor in implementing an MIS system, as meta-analysis revealed that organizational readiness was strongly correlated to technology implementation. Hameed et al's study also concluded that organizational readiness is the most significant organizational factor for adopting or implementing a new MIS system (2012) [14].

Another study conducted by Weiner (2009) stated that organizational readiness is "a shared psychological state in which organizational members feel committed to implementing an organizational change and confident in their collective abilities to do so" (p. 3). It's important to include employee perceptions of the process [15].

Wayne et al. (2002) provided an assessment of organizational readiness by focusing on motivation of employees and program leader's personal attributes. The study also stated that organizational climate plays an important role in understanding factors related to implementing a new technology system. The study surveyed more than 500 personnel and determined that organization readiness can contribute to organizational change and new technology implementation.

Employee perceptions related to an organization's readiness for change is considered the most important factor in understanding sources of resistance to large-scale changes such as the new implementation of an MIS [7] [16] Prior research has focused on the impact of an MIS on the organization's employees' perceived value [16]. However, the same literature typically lacks information on organizational factors that must be present if an organization is to be considered ready for a new technology system. This is especially true in the nonprofit industry.

\subsection{Organizational Climate}

Organizational climate is defined as a "set of characteristics that describe an organization and that: 1) distinguish the organization from other organizations, 2) are relatively enduring over time, and 3) influence the behavior of people in the organization" [17]. Organizational climate could also be defined as a variable that includes size, structure, system complexity, leadership style, and goal directions, as well as common practices, shared beliefs, and value systems that an organization follows [18].

In a study examining how the organizational climate influences an organization's readiness to implement new technology, [19] explains that an organization that is viewed by its employees as rigid and unwilling to change takes a different approach to adopting a new technology implementation than an organization 
whose employees view as open and non-resistant to change. The same study by Bellamy also states, "The perceived climate of the organization may mediate the relationship among technology, the planning processes, and the perceived effectiveness of the deployment of technology" [19]. As a result, it is a critical aspect in this study for measuring organizational climate.

This study will examine two dimensions of the BOCI [20]: open-mindedness and questioning authority. These two dimensions were chosen among 17 factors within BOCI because of their relevance to the study of technology implementation.

\subsection{Organizational Structure}

Organizational structure is defined as " $\ldots$ the sum total of the ways in which it divides its labor into distinct tasks and then achieves coordination among them" [21]. Wilson and Rosenfield defined organizational structure as the established pattern of relationships between an organization's components parts, including communication, control, and authority patterns (1990).

Organizational structure helps to shape an organization's behavioral pattern because it creates formal and informal relationships, roles, and activities among the organization's employees. Organizational structure determines an organization's readiness to implement a new system by establishing the system that the new MIS will be following or using for a successful implementation process. As a result, it's a very important factor to include in this study.

Organizational structure configuration greatly affects its readiness to change [22]. Each type of structure has a different relationship to the organization's policies, activities, and members. Studies have shown that three of the structuring components-formalization, centralization, and specialization-are commonly considered to be important influences on organizational performance [20]. This study of organizational structure will consist of examining organizational centralization, integration, and formalization.

Centralization refers to the extent to which decision-making comes from top levels of the organization [23]. Decentralization has been found effective for more communication within the organization, as it increases employee satisfaction [24]. This, in turn, could also affect employees' willingness to accept new technology.

Formalization. Organizational formalization refers to the extent to which rules and procedures of an organization are written down, including a member's rights and duties.

Formalization is also described as "the degree to which an organization follows the rules and procedures on the role of performance of its members" [14]. According to Hameed et al.'s meta-analysis, formalization has no significance with IT implementation adoption.

Some studies have shown that formalization improves organizational performance [25] [26]. Centralization and formalization are mostly found in the form of formal hierarchical coordination. This study postulated that a high level of 
formalization would have positive impact on the implementation of technology within an organization.

A study by Tworek (2014) examined 105 organizations operating in Poland that had implemented an IT system. Four organizational structure dimensions were included within the study consisting of hierarchy, centralization, formalization and specialization [27]. The study found that a correlation exists between IT acceptance and the hierarchy's complexity and degree of centralization IT acceptance was associated with organic organizational structures. These findings support the goal of this current study to analyze the impact of organization structure on employee technology acceptance [28].

\subsection{Employees' Perceptions of Psychological Contract}

According to Charissa and Croon (2001), employees' perceptions of their psychological contract are defined as "the exchange relationship between employee and organization, concerning mutual obligations in the employment relationship as perceived by the employee" (p. 405) [29]. Employee perceptions of their psychological contract could also be defined as a "set of reciprocal obligations or promises related to employment relationship" Several studies have shown that employee perceptions of their psychological contract is often violated, especially during a change process or organizational transformation process [30]. A number of research studies have also examined how psychological contracts are greatly affected during an organization change such as a new technology implementation.

\subsection{Technology Implementation Strategy}

Technology implementation strategy within the context of this study "relates to the extent in which the organization has strategically approached the deployment of its new technology(s) and the manner in which it has prepared for the execution of its technologies prior to their implementation through planning and assessment" [30].

Technology implementation strategy leads to a strategic balance between external implementation of IT strategy and the internal implementation of the IT infrastructure and processes. According to Kochan (1992), it "involves the assessment of the implications of implementing the chosen business strategy by appropriate organizational infrastructure and management processes as well as the design and development of the required internal IT infrastructure and processes" (p. 758) [31].

This study will examine two dimensions of technology implementation strategy: planning and assessment processes.

\subsection{Technology Acceptance}

Technology acceptance is one of the most significant factors that impacts IT system implementations processes [32] and one of the most critical factors for a 
successful IT system implementation [33]. The users' intentions for the information technology will determine both its usefulness and ease of use [34]. According to Katzenbeisser (2012), perceived usefulness is defined as "the degree to which an individual believes that using a particular system would enhance his or her job performance," and perceived ease of use is "the degree to which an individual believes that using a particular system would be free of physical and mental effort" (p. 95) [35].

Understanding technology acceptance and the use of IT systems in the workplace offers many benefits to any organization and includes the following: enhancing the organizational performance with the use of the IT system to complement the human resources aspect and minimizing the impact associated with organizational change involving IT systems [36].

\section{Research Questions}

1) What is the relationship between organizational climate and employee technology acceptance?

- What is the relationship between open-mindedness and employee technology acceptance?

- What is the relationship between questioning authority and employee technology acceptance?

2) What is the relationship between organizational structure and employee technology acceptance?

- What is the relationship between organizational centralization and employee technology acceptance?

- What is the relationship between organizational integration and employee technology acceptance?

- What is the relationship between organizational formalization and employee technology acceptance?

3) What is the relationship between technology implementation strategy and employee technology acceptance?

- What is the relationship between organizational involvement of the new implementation process from the beginning, starting with the planning phase, and employee technology acceptance?

- What is the relationship between user's involvement in the planning of a new MIS system implementation and employee technology acceptance?

4) What is the relationship between employee perceptions of their psychological contract and employee technology acceptance?

\section{Methodology}

\subsection{Population and Sampling}

A sample of 100 employees from three different nonprofit organizations located in Southeastern Michigan, that were employed as MIS users. Employees from different departments, including caseworkers, coordinators, and administrative 
employees, were invited to participate. All employees were chosen based on their department and availability .A convenience sample was used, and participation was voluntary. Five departments in each organization were represented in the study:

1) Finance (Fiscal office)

2) Mental Health Department

3) Employment and Training Department

4) Social Services Department

5) Information Technology Department

The demographic composition of the sample is as follows: $73 \%$ were female, and $27 \%$ were male; $61 \%$ were younger than 40 , and $32 \%$ were between the ages of 41 and 60. Eighty-four percent of participants were working full time, 14\% were employed part-time, half of the survey participants had completed their bachelor's degrees, $29 \%$ had earned their master's degrees, and 6\% had obtained advanced graduate work. $40.4 \%$ of the samples were case managers, $23 \%$ program coordinators, $4 \%$ directors, and $32 \%$ consisted of other positions.

\subsection{Instruments and Measurements}

Data were collected through an online survey based on Google forms. After all the data had been collected, they were transferred to a spreadsheet into the Statistical Package for Social Sciences (SPSS) for analysis.

The organizational climate scale consisted of 10 items. The scale ranged from a score of 7 (strongly agree) to 1 (strongly disagree) with seven anchor points. Two dimensions of organizational climate were measured, consisting of open-mindedness and questioning of authority, extracted from the Organization Climate Index [21]. The scale for measuring technology acceptance consisted of 6 items. The technology acceptance model (TAM)) scale was used to measure technology acceptance. The scale ranges from a score of 7 (strongly agree) to 1 (strongly disagree) with seven anchor points. The dimensions used are users' perceptions $s$ of the system's job and the ease of use of the system and the scale consisted of 6 items [20].

Technology acceptance will be measured by two outcome variables: users' perceptions s of the system's job and the ease of use of the system. Perceived ease of use is listed on the Technology Acceptance Model (TAM) as a direct determinant of perceived usefulness, which is also linked to increased job performance (Davis, 1989) [36].

The technology implementation strategy scale consisted of 14 items [19]. The scale ranged from a score of 7 (strongly agree) to 1 (strongly disagree) with seven anchor points. The dimensions used are organization readiness factors when an organization's new technology implementation was factored in during the planning stages of the most recent new technology implementation within an organization.

The questionnaire for measuring organizational structure included 10 items. Three dimensions of organizational structure variables were examined: formali- 
zation, integration, and centralization. The scale will range from a score of 7 (strongly agree) to 1 (strongly disagree) with a seven-point anchor. Organizational readiness will be measured by examining organizational climate, structure, and implementation strategy.

Employee perceptions of their psychological contract measuring scale includes 7 items; the scale will range from a score of 7 (strongly agree) to 1 (strongly disagree) with a seven-point anchor (20).

\subsection{Reliability of the Questionnaire (Scales)}

In this study, Cronbach's alpha was calculated for each scale to test the reliability and to measure internal consistency of the entire questionnaire. The following is description of the reliability

For each of the scales:

Open mindedness climate -0.88

Questioning authority climate- -0.82

Centralization -0.83

Formalization -0.78

Implementation strategy-0.95

Psychological contract- 0.95

Technology acceptance- -0.92

\section{Results}

Research Question 1. What is the relationship between organizational climate and technology acceptance?

- What is the relationship between open-mindedness and employee technology acceptance?

- What is the relationship between questioning authority and employee technology acceptance?

As revealed in Table 1 , there is a statistically significant relationship between organizational climate and technology acceptance, as the correlation is (0.461). There is a relationship between employee technology acceptance and organizational climate on two dimensions, open-mindedness and questioning authority, which equal 0.433 and 0.395 , respectively. This means that an increase of organizational climate variables equals an increase in employee technology acceptance.

Research Question 2. What is the relationship between organizational structure and employee technology acceptance?

- What is the relationship between organizational centralization and employee technology acceptance?

- What is the relationship between organizational formalization and employee technology acceptance?

Table 1 reveals a significant correlation between organizational structure and employee technology acceptance. The correlation coefficient is 0.410 and $\alpha=$ 0.05 . A positive correlation was found between employee technology acceptance 
Table 1. Pearson correlations between organizational structure, organizational climate, technology implementation strategy and employee perceptions of their psychological contract on technology acceptance and outcome variables for entire sample $(\mathrm{N}=100)$.

\begin{tabular}{ll}
\hline \multicolumn{2}{c}{ Employee Technology Acceptance } \\
\hline Organizational Climate Combined & $0.46^{\star}$ \\
1. Open Mindedness & $0.43^{\star}$ \\
2. Questioning Authority & $0.40^{\star}$ \\
Technology Implementation Combined & $0.34^{\star}$ \\
3. Implementation Strategy & $0.27^{\star}$ \\
4. New Implementation & $0.38^{\star}$ \\
Organizational Structure Combined & $0.41^{\star}$ \\
5. Centralization & $0.34^{\star}$ \\
6. Formalization & $0.37^{\star}$ \\
7. Employee perceptions of their psychological contract & $0.43^{\star}$ \\
\hline
\end{tabular}

$\mathrm{n}=100,{ }^{*}$ Significant at the $\leq 0.001, p$-value level.

and organizational structure factors (organizational centralization, organizational integration, and organizational formalization), as the correlation factors are $0.337,0.380$, and 0.380 , respectively. This is somewhat contrary to our expectations. We thought that both centralization and formalization would produce a "mechanistic" and inflexible environment. We felt that a flexible structure would be more conducive to employees accepting a new MIS system. However, it appears that higher levels of centralization and formalization serve the function of providing clarity and direction to employees and this would in turn enhance the employee acceptance of new technology.

Research Question 3. What is the relationship between technology implementation strategy and employee technology acceptance?

- What is the relationship between organizational involvement of the new implementation process from the beginning starting with the planning phase and employee technology acceptance?

- What is the relationship between user's involvement of the implementation process and employee technology acceptance?

As demonstrated in Table 1 a statistically significant correlation between employee technology acceptance and implementation strategy is revealed. A positive correlation means that an increase in technology implementation strategy and its factors led to an increase in employee technology acceptance.

Research Question 4. What is the relationship between employee perceptions of their psychological contract and employee technology acceptance?

As shown in Table 1, a statistically significant correlation exists between employee perceptions of their psychological contract and employee technology acceptance, as the correlation equals $(0.342)$. A positive correlation means that an increase in employee perceptions of their psychological contract leads to an increase 
in employee technology acceptance.

\section{Discussion}

The purpose of this study was to determine whether there is an effect on employee technology acceptance within nonprofit organizations related to organizational readiness consisting of organizational climate, organizational structure, technology implementation strategy, and employee perceptions of their psychological contract.

The study's key findings include the following: a relationship between organizational climate and employee technology acceptance was shown to be statistically significant. With regard to organizational climate and employee technology acceptance, this study revealed a relationship with the highest positive correlation, which means that an increase of organizational climate variables equals an increase in employee technology acceptance variables.

The study plays an important role in providing information that is not common within the field of organizational study. As far as we know, it is the only study that includes employee's perception of the psychological contract as a factor in a technology study. Our study has indicated that this factor has a significant influence on employee's acceptance of MIS technology. Subsequently, this is a factor that organizations, and particularly non-profit organizations should systematically consider when contemplating the deployment of a MIS system.

The study also found statistically significant correlations between organizational structure factors, implementation strategy, and organizational climate with employee acceptance of technology. This finding supports the idea that these factors can function as critical variables for an organization readiness assessment of MIS implementation. We recommend that other factors should be included in future empirical investigations of this type.

\section{References}

[1] Munir, K.A. and Phillips, N. (2002) The Concept of Industry and the Case of Radical Technological Change. The Journal of High Technology Management Research, 13, 279-297. https://doi.org/10.1016/S1047-8310(02)00046-9

[2] Milis, K. and Mercken, R. (2002) Success Factors Regarding the Implementation of ICT Investment Projects. International Journal of Production Economics, 80, 105-117. https://doi.org/10.1016/S0925-5273(02)00246-3

[3] Decker, P., Durand, R., Mayfield, C.O., McCormack, C., Skinner, D. and Perdue, G. (2012) Predicting Implementation Failure in Organization Change. Journal of Organizational Culture, Communication and Conflict, 16, 29-49.

http://ezproxy.emich.edu/login?url=http://search.proquest.com/docview/103798598 4 ? accountid $=10650$

[4] Bouckenooghe, D., Devos, G. and Van den Broeck, H. (2009) Organizational Change Questionnaire-Climate of Change, Processes, and Readiness: Development of a New Instrument. The Journal of Psychology, 143, 559-599.

http://ezproxy.emich.edu/login?url=http://search.proquest.com/docview/213828176 ?accountid $=10650$

https://doi.org/10.1080/00223980903218216 
[5] Blau, A. (2001) More than Bit Players: How Information Technology Will Change the Ways Nonprofits and Foundations Work and Thrive in the Information Age. Surdna Foundation. http://www.surdna.org/usrdoc/morefinal.pdf

[6] Finn, S., Maher, J.K. and Forster, J. (2006) Indicators of Information and Communication Technology Adoption in the Nonprofit Sector. Nonprofit Management \& Leadership, 16, 277-295. https://doi.org/10.1002/nml.107

[7] Saigal, A. (2008) A Study on the Impact of Information Technology Use on Non-Profit Organizations. Order No. 1455975, Grand Valley State University. ProQuest Dissertations and Theses, 70-n/a.

http://ezproxy.emich.edu/login?url=http://search.proquest.com/docview/304304366 ?accountid=10650

[8] Salamon, L.M., Sokolowski, S.W. and List, R. (2003) Global Civil Society: An Overview. Center for Civil Society Studies, Institute for Policy Studies, The Johns Hopkins University, Baltimore, MD.

[9] Armstrong, A. and Foley, P. (2003) Foundations for a Learning Organization: Organization Learning Mechanisms. The Learning Organization, 10, 74-82.

[10] Crump, B. and Peter, R. (2014) A Case for Non-Profit Organisations to Engage in the Use of Shared Computing Services. Electronic Journal of Information Systems Evaluation, 17, 15-22.

http://ezproxy.emich.edu/login?url=http://search.proquest.com/docview/155535517 $\underline{3 \text { ? accountid }=10650}$

[11] Haddad, C.R., Ayala, D.H.F., Uriona Maldonado, M., Forcellini, F.A. and Lezana, Á.G.R. (2016) Process Improvement for Professionalizing Non-Profit Organizations: BPM Approach. Business Process Management Journal, 22, 634-658. https://doi.org/10.1108/BPMJ-08-2015-0114

[12] Schneider, J.A. (2003) Small, Minority-Based Nonprofits in the Information Age. Nonprofit Management and Leadership, 13, 383-399. https://doi.org/10.1002/nml.6

[13] Jaskyte, K. (2012) Exploring Potential for Information Technology Innovation in Nonprofit Organizations. Journal of Technology in Human Services, 30, 118-127. https://doi.org/10.1080/15228835.2012.695564

[14] Hameed, M.A., Counsell, S. and Swift, S. (2012) A Meta-Analysis of Relationships between Organizational Characteristics and IT Innovation Adoption in Organizations. Information \& Management, 49, 218-232. https://doi.org/10.1016/j.im.2012.05.002

[15] Weiner, B.J. (2009) A Theory of Organizational Readiness for Change. Implementation Science, 4, 67. https://doi.org/10.1186/1748-5908-4-67

[16] McDonald, T. and Siegal, M. (1993) Enhance Self-Efficacy. Training and Development Journal, 48, 66-67.

[17] Iacovini, J. (1993) The Human Side of Organization Change. Training and Development Journal, 47, 65-68.

[18] Xie, D. (2007) A Study of Teacher Leadership and Its Relationship with School Climate in American Public schools: Findings from SASS 2003-2004.

[19] Zohar, D. and Luria, G. (2004) Climate as a Social-Cognitive Construction of Supervisory Safety Practices: Scripts as Proxy of Behavior Patterns. Journal of Applied Psychology, 89, 322-333. https://doi.org/10.1037/0021-9010.89.2.322

[20] Payne, R.L. and Mansfield, R. (1973) Relationships of Perceptions s of Organizational Climate to Organizational Structure, Context and Hierarchical Position. Administrative Science Quarterly, 18, 515-526. https://doi.org/10.2307/2392203 
[21] Mintzberg, H. (1993) Structure in Fives: Designing Effective Organizations. Prentice-Hall, Englewood Cliffs, NJ.

[22] Chen, G. and Tjosvold, D. (2008) Organizational Values and Procedures as Antecedents for Goal Interdependence and Collaborative Effectiveness. Asia Pacific Journal of Management, 25, 93-112. https://doi.org/10.1007/s10490-007-9038-3

[23] Chatzoglou, P.D., Diamantidis, A.D., Vraimaki, E., Vranakis, S.K. and Kourtidis, D.A. (2011) Aligning IT, strategic Orientation and Organizational Structure. Business Process Management Journal, 17, 663-687. https://doi.org/10.1108/14637151111149474

[24] Caruana, A., Morris, M.H. and Vella, A.J. (1998) The Effect of Centralization and Formalization on Entrepreneurship in Export Firms. Journal of Small Business Management, 36, 16-29.

[25] Burns, T. and Stalker, M. (1961) The Management of Innovation. Tavistock Publications, London.

[26] Nahm, A.Y., Vonderembse, M.A. and Koufteros, X.A. (2003) The Impact of Organizational Structure on Time-Based Manufacturing and Plant Performance. Journal of Operations Management, 21, 281-306. https://doi.org/10.1016/S0272-6963(02)00107-9

[27] Pearce, J.A., Robbins, D.K. and Robinson, R.B. (1987) The Impact of Grand Strategy and Planning Formality on Financial Performance. Strategic Management Journal, 8, 125-134. https://doi.org/10.1002/smj.4250080204

[28] Tworek, K. (2014) Wpływ technologii informacyjnych na struktury organizacyjne przedsiębiorstw. Ph.D. Thesis, Wroclaw University of Technology, Wroclaw.

[29] Freese, C., Schalk, R. and Croon, M.A. (2011) The Impact of Organizational Changes on Psychological Contracts: A Longitudinal Study. Personnel Review, 40, 404-422.

[30] Menghrajani, E.M. (2011) Examination of the Relationship between User Participation and Technology Acceptance in Post-Implementation. Order No. 1505732, San Jose State University, ProQuest Dissertations and Theses, 61. http://ezproxy.emich.edu/login?url=http://search.proquest.com/docview/920120937 ?accountid $=10650$

[31] Legris, P., Ingham, J. and Collerette, P. (2003) Why Do People Use Information Technology? A Critical Review of the Technology Acceptance Model. Information \& Management, 40, 191-204. https://doi.org/10.1016/S0378-7206(01)00143-4

[32] Boakye, G., McGinnis, T. and Prybutok, V. (2014) Q-TAM: A Quality Technology Acceptance Model for Technology Operations Managers. Operations Management Research, 7, 13-23. https://doi.org/10.1007/s12063-014-0085-x

[33] Katzenbeisser, S. (2012) Trust and Trustworthy Computing. Proceedings of the 5th International Conference, TRUST2012, Vienna, Austria, 13-15 June 2012. https://doi.org/10.1007/978-3-642-30921-2

[34] Henderson, J.R. and Ruikar, K. (2010) Technology Implementation Strategies for Construction Organisations. Engineering, Construction and Architectural Management, 17, 309-327. https://doi.org/10.1108/09699981011038097

[35] Venkatesh, V. and Davis, F.D. (2000) A Theoretical Extension of the Technology Acceptance Model: Four Longitudinal Field Studies. Management Science, 46, 186-204. https://doi.org/10.1287/mnsc.46.2.186.11926

[36] Davis, F.D. (1989) Perceived Usefulness, Perceived Ease of Use, and User Acceptance of Information Technology. MIS Quarterly, 13, 319-339. 